\title{
NMDA Receptor-Dependent Afterdepolarizations Are Curtailed by Carbonic Anhydrase 14: Regulation of a Short-Term Postsynaptic Potentiation
}

\author{
Sachin Makani, ${ }^{1 \star}$ Huei-Ying Chen, ${ }^{1 \star}$ Susana Esquenazi, ${ }^{1}$ Gul N. Shah, ${ }^{3}$ Abdul Waheed ${ }^{4}$ William S. Sly, ${ }^{4}$ \\ and Mitchell Chesler ${ }^{2}$ \\ Departments of ${ }^{1}$ Physiology and Neuroscience and ${ }^{2}$ Neurosurgery, New York University School of Medicine, New York, New York 10016, and ${ }^{3}$ Department \\ of Internal Medicine, Division of Nephrology and ${ }^{4}$ Edward A. Doisy Department of Biochemistry and Molecular Biology, St. Louis University School of \\ Medicine, St. Louis, Missouri 63104
}

In the hippocampus, extracellular carbonic anhydrase (Car) speeds the buffering of an activity-generated rise in extracellular pH that impacts $\mathrm{H}^{+}$-sensitive NMDA receptors (NMDARs). We studied the role of Car14 in this brain structure, in which it is expressed solely on neurons. Current-clamp responses were recorded from CA1 pyramidal neurons in wild-type (WT) versus Car14 knock-out (K0) mice $2 \mathrm{~s}$ before (control) and after (test) a 10 pulse, $100 \mathrm{~Hz}$ afferent train. In both WT and KO, the half-width (HW) of the test response, and its number of spikes, were augmented relative to the control. An increase in presynaptic release was not involved, because AMPAR-mediated EPSCs were depressed after a train. The increases in $\mathrm{HW}$ and spike number were both greater in the Car14 $\mathrm{KO}$. In $0 \mathrm{Mg}^{2+}$ saline with picrotoxin (using a $20 \mathrm{~Hz}$ train), the $\mathrm{HW}$ measures were still greater in the KO. The Car inhibitor benzolamide (BZ) enhanced the test response HW in the WT but had no effect on the already-prolonged HW in the K0. With intracellular MK-801 [(+)-5-methyl-10,11dihydro-5H-dibenzo [a,d]-cyclohepten-5,10-imine maleate], the curtailed WT and KO responses were indistinguishable, and BZ caused no change. In contrast, the extracellular alkaline changes evoked by the train were not different between WT and K0, and BZ amplified these alkalinizations similarly. These data suggest that Car14 regulates $\mathrm{pH}$ transients in the perisynaptic microenvironment and govern their impact on NMDARs but plays little role in buffering $\mathrm{pH}$ shifts in the broader, macroscopic, extracellular space.

\section{Introduction}

A rapid increase in extracellular $\mathrm{pH}\left(\mathrm{pH}_{\mathrm{e}}\right)$ often accompanies synchronous neural activity (Chesler, 2003). This population alkaline transient (PAT) is generated by exchange of external $\mathrm{H}^{+}$ for cytosolic $\mathrm{Ca}^{2+}$ via the neuronal plasma membrane $\mathrm{Ca}^{2+}$ ATPase (PMCA) (Schwiening et al., 1993; Makani and Chesler, 2010). The extracellular carbonic anhydrase (Car) isoforms Car4 and Car14 govern the PAT magnitude (Shah et al., 2005), as $\mathrm{H}^{+}$ that leaves the extracellular space is replenished through the catalyzed reaction:

$$
\mathrm{CO}_{2}+\mathrm{H}_{2} \mathrm{O} \leftrightarrow \mathrm{HCO}_{3}^{-}+\mathrm{H}^{+} .
$$

Benzolamide (BZ), a poorly-permeant Car inhibitor, decreases the rate of $\mathrm{H}^{+}$replenishment, amplifying the PAT (Chen and

Received March 26, 2012; revised Aug. 23, 2012; accepted Sept. 23, 2012.

Author contributions: S.M., H.-Y.C., and M.C. designed research; S.M., H.-Y.C., and S.E. performed research; S.M.,

H.-Y.C., S.E., G.N.S., A.W., W.S.S., and M.C. analyzed data; S.M. and M.C. wrote the paper.

*S.M. and H.-Y.C. contributed equally to this work.

This work was supported by National Institutes of Health Grants NS32123 (M.C.) and GM034182 (W.S.S., G.N.S. A.W.), National Research Service Award F31 Grant NS-058152 (S.M.), and the Attilio and Olympia Ricciardi Fund (H.-Y.C.).

Correspondence should be addressed to Dr. Mitchell Chesler, Department of Physiology and Neuroscience, New York University School of Medicine, 550 First Avenue, New York, NY 10016. E-mail: mitchell.chesler@nyumc.org. DOI:10.1523/JNEUROSCI.1467-12.2012

Copyright $\odot 2012$ the authors $\quad 0270-6474 / 12 / 3216754-09 \$ 15.00 / 0$
Chesler, 1992a), whereas addition of exogenous Car suppresses this alkalosis (Huang et al., 1995; Tong et al., 2006). These means of modulating buffering capacity were correlated with respective enhancement or curtailment of postsynaptic responses mediated by NMDA receptors (NMDARs) (Gottfried and Chesler, 1994; Fedirko et al., 2007; Makani and Chesler, 2007), which are steeply inhibited by protons near physiological pH (Tang et al., 1990; Traynelis and Cull-Candy, 1990; Vyklick ý et al., 1990).

In the hippocampus, Car14 is confined to neurons (Parkkila et al., 2001). In slices from Car14 knock-out (KO) mice, the PAT elicited by antidromic activation of pyramidal neurons was not different from that of wild type (WT), suggesting that the role of Car14 in buffering the macroscopic compartment is minor (Shah et al., 2005). However, in view of the high activity of this enzyme (Whittington et al., 2004), it might catalyze buffering in neuronal microdomains that would be inaccessible to a $\mathrm{pH}$ electrode. If this occurred in the vicinity of NMDARs, then specific alterations in postsynaptic responses might be exhibited in animals lacking Car14. The regenerative afterdepolarization (ADP) of pyramidal neurons has a large NMDAR-mediated component and is especially sensitive to changes in extracellular buffering capacity (Fedirko et al., 2007; Makani and Chesler, 2007). We therefore investigated whether the orthodromic response of CA1 pyramidal neurons is altered by the absence of Car14.

We report that, when a brief, orthodromic train preceded a single test pulse by $2 \mathrm{~s}$, the ADP of the test response was prolonged and 
contained more action potentials in both WT and Car14 KO. This effect lasted seconds, did not have a presynaptic origin, and was greater in the Car14 KO. In $0 \mathrm{Mg}^{2+}$ saline, the post-train effect was exaggerated, still greater in the $\mathrm{KO}$, and this phenotypic difference was abolished when NMDARs were blocked by intracellular MK801 [(+)-5-methyl-10,11-dihydro-5H-dibenzo [a,d]-cyclohepten5,10-imine maleate]. Additional differences were revealed by BZ, which greatly broadened the test response in the WT but had no effect on the already-prolonged ADP in the KO. Despite the disparities observed in the whole-cell responses, orthodromic trains elicited an equivalent PAT in WT and $\mathrm{KO}$, before and after amplification by BZ. We suggest that Car14 curtails alkaline transients in the perisynaptic microenvironment, thereby limiting their impact on postsynaptic excitability.

\section{Materials and Methods}

All procedures were performed with the approval of the New York University School of Medicine Institutional Animal Care and Use Committee.

Animals. Derivation and genotyping of the Car14 mouse have been described previously (Shah et al. 2005). Colonies were backcrossed into a C57BL/6 background, and WT and KO littermates obtained by hemizygous pairing. Animals were genotyped before P7 and used for experiments at P12-P18. Mice of either gender were used for experiments.

Experimental preparation and solutions. Hippocampal slices, $250 \mu \mathrm{m}$ thick, were prepared as described previously (Makani and Chesler, 2007). Recordings were conducted in a submersion-style incubation chamber at $32^{\circ} \mathrm{C}$. A small cut was made between the CA 3 and CA1 regions to prevent reverberating discharges from CA3 neurons. The slices were incubated for at least $1 \mathrm{~h}$ at room temperature in standard ACSF that contained the following (in mM): $124 \mathrm{NaCl}, 3.0 \mathrm{KCl}, 2.0 \mathrm{CaCl}_{2}, 1.5 \mathrm{MgCl}_{2}, 26 \mathrm{NaHCO}_{3}$, $1.0 \mathrm{NaH}_{2} \mathrm{PO}_{4}$, and 10 D-glucose, with $\mathrm{pH} 7.4$ (equilibrated with $95 \% \mathrm{O}_{2}$ and $5 \% \mathrm{CO}_{2}$ ).

Drugs were added to either the external ACSF or the intracellular pipette solution, as noted, in the following concentrations: BZ $(10 \mu \mathrm{M})$, MK-801 (1 mM), picrotoxin (100 $\mu \mathrm{M})$, and nystatin $(300 \mu \mathrm{g} / \mathrm{ml})$. BZ was a gift from Dr. Erik Swenson (University of Washington, Seattle, WA). All other agents were obtained from Sigma-Aldrich.

Concentric $\mathrm{pH}$-selective microelectrodes. $\mathrm{pH}$-selective microelectrodes (tip diameter, 4-6 $\mu \mathrm{m}$ ) with response times on the order of 10-20 ms were fabricated, calibrated, and used with separate reference microelectrodes as detailed by Fedirko et al. (2006). $\mathrm{pH}_{\mathrm{e}}$ recordings were performed in the CA1 stratum radiatum. The $\mathrm{pH}$ and reference microelectrodes were mounted on a dual micromanipulator with a tip separation of 5-10 $\mu \mathrm{m}$. The dual array was then advanced until the evoked orthodromic field potential was maximal, which was typically at a depth of $100-150 \mu \mathrm{m}$. The stimulating and recording electrodes were $100-150 \mu \mathrm{m}$ from the CA1 cell body layer and 200 $\mu \mathrm{m}$ from each other. Direct current potentials recorded on the reference barrel were continuously subtracted from the $\mathrm{pH}$ recording, and the resulting $\mathrm{pH}$ signal was filtered at $2 \mathrm{kHz}$.

Evoked whole-cell responses. Recordings were performed from hippocampal CA1 pyramidal cells visualized under an infrared differential interference contrast microscope as described previously (Makani and Chesler, 2007). In current clamp, whole-cell patch pipettes were filled with the following (in $\mathrm{mm}$ ): $120 \mathrm{~K}$-gluconate, $20 \mathrm{KCl}, 2.0 \mathrm{MgCl}_{2}, 25$ $\mathrm{Na}$-HEPES, and $2 \mathrm{Mg}_{2}$-ATP. Pipettes in voltage-clamp experiments contained the following (in mM): 130 Cs-gluconate, $20 \mathrm{KCl}, 20 \mathrm{Na}$-HEPES, 2 MgATP, and 4 QX-314 [2(triethylamino)- $N$-(2,6-dimethylphenyl) acetamine]. After adjusting the $\mathrm{pH}$ of filling solutions to 7.3 with $\mathrm{KOH}$ or $\mathrm{CsOH}$, respectively, the final osmolarity was $280-290 \mathrm{mOsm}$. Some experiments were performed in the perforated-patch configuration, in which nystatin $(300 \mu \mathrm{g} / \mathrm{ml})$ was added to the intracellular solution. There was no difference in current-clamp results, whether obtained in conventional whole-cell (breakthrough) mode or perforated patch, and therefore data from these two approaches were combined. In current clamp, data were accepted if cells had an initial resting membrane potential of at least $-50 \mathrm{mV}$. Hyperpolarizing or depolarizing current was injected as required to bring the membrane potential to nominal -65 $\mathrm{mV}$ before the start of the experiment. Traces were sampled at $5 \mathrm{kHz}$ and filtered at $2 \mathrm{kHz}$.

The Schaffer collateral fibers were activated by constant-current pulses of $200 \mu$ s duration, delivered by a twisted pair of $50-\mu$ m-diameter Teflon-insulated platinum-iridium wires. The majority of experiments in normal ACSF used a single control stimulus, followed at $2 \mathrm{~s}$ by a 10 pulse, $100 \mathrm{~Hz}$ train, followed $2 \mathrm{~s}$ after the onset of the train by a single test stimulus. In $0 \mathrm{Mg}^{2+}$ experiments, a 10-pulse, $20 \mathrm{~Hz}$ train was followed by a test response at $2 \mathrm{~s}$. When using MK-801 in the patch pipette, these periodic stimulation paradigms were performed while the cell was dialyzed, permitting the open channel block of NMDARs to develop.

Adjustment of stimulus intensity. The efficacy of a stimulus at any given intensity can vary between cells and slices because of differences in electrode placement, angle of trajectory of the Schaffer collaterals, or other factors intrinsic to the individual animal or slice. In many protocols, one would simply use a supramaximal stimulus to ensure comparable stimulus efficacy. This was our approach in comparing the evoked PAT among slices. In current-clamp experiments, however, a supramaximal stimulus was not practical because of the nature of the stimulus paradigm. In normal ACSF, we used a single control stimulus, followed at $2 \mathrm{~s}$ by a 10 -stimulus, $100 \mathrm{~Hz}$ conditioning train, followed after another $2 \mathrm{~s}$ by a single test stimulus (see Results). This protocol was repeated three to five times at a $50 \mathrm{~s}$ interval. The response to the train consisted of a burst of spikes, followed by a prolonged, regenerative ADP that was highly variable among neurons. To reasonably compare the control and test responses, it was essential that the membrane potential recover to resting potential after the ADP of the train response. Stimulus intensity was therefore adjusted to a level at which the ADP would return to rest $\sim 1 \mathrm{~s}$ before the test stimulus. The resulting half-width (HW) of the control response and the train response was no different in WT versus Car $14 \mathrm{KO}$, indicating parity of the stimulus among slices. In $0 \mathrm{Mg}^{2+}$ experiments, the stimulus protocol was abbreviated, consisting of just a 10 -stimulus, $20 \mathrm{~Hz}$ conditioning train followed after $2 \mathrm{~s}$ by a test stimulus. Stimulus intensity was again adjusted to ensure that the ADP had fully recovered to resting potential before the test response, but the time at which this recovery occurred could not be controlled with the same precision as in normal ACSF because of the increased in excitability and longer duration of the regenerative train response in $0 \mathrm{Mg}^{2+}$ saline. Nonetheless, the mean HWs of the train responses were not significantly different in WT versus Car14 KO. To achieve additional parity in the analysis, test response HWs and spike numbers were normalized to the HW of the preceding train response, as described in Results.

Data analyses. Statistics were presented as means with SE. Values of $n$ refer to the number of neurons or slices, as indicated. Comparisons between mean values were made with a two-tailed, Student's paired or unpaired $t$ test or with multiple comparisons, as appropriate. The HW of postsynaptic responses was based on half the difference between the prestimulus resting potential and the peak of the ADP. Measurements were made from three to five averaged traces. Single representative traces were used for figures. Significance levels in the figures were designated as ${ }^{*} p<0.05,{ }^{* *} p<0.01$, and ${ }^{* * *} p<0.001$.

\section{Results}

\section{Whole-cell responses in normal ACSF}

To uncover a phenotypic difference in the absence of a Car isoform, we reasoned that the extracellular alkaline transient elicited by a $100 \mathrm{~Hz}$ orthodromic stimulus train would persist for a few seconds in the peri-neuronal space (Tong et al., 2006). In the absence of catalyzed buffering via Car14, the magnitude and duration of this post-train alkalosis might be larger in the vicinity of postsynaptic NMDAR receptors. Accordingly, the postsynaptic response to a stimulus that followed the train might be augmented in the Car $14 \mathrm{KO}$ relative to WT.

In initial experiments, a single control stimulus was given $2 \mathrm{~s}$ before the onset of a 10-pulse, $100 \mathrm{~Hz}$ conditioning train. At $2 \mathrm{~s}$ after the onset of the train, a single test stimulus was given (Fig. 1). 
A

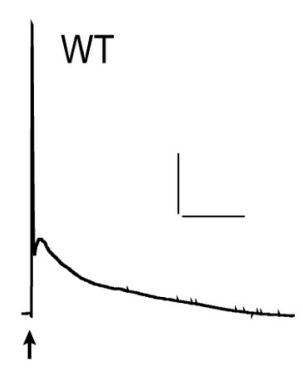

Control

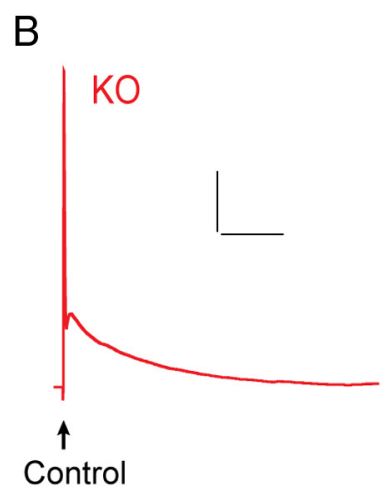

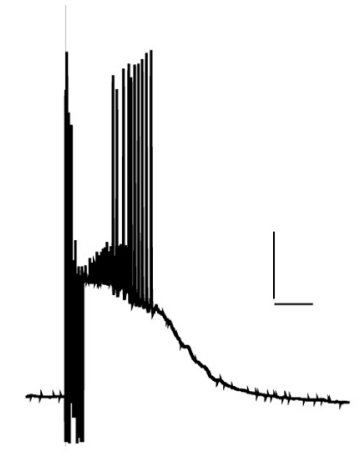

$10 @ 100 \mathrm{~Hz}$

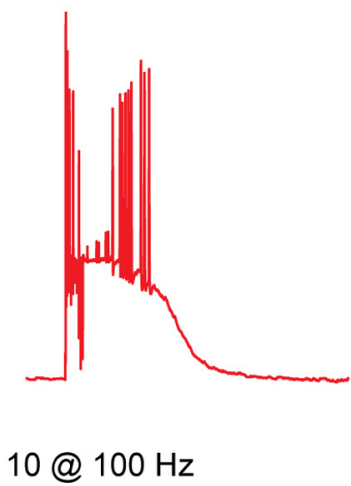

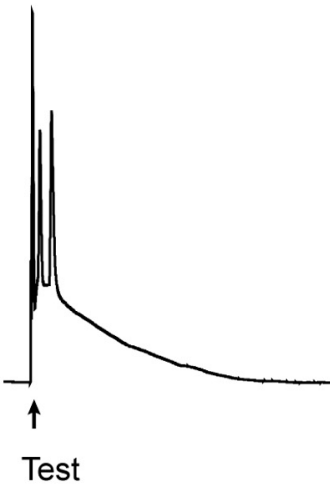
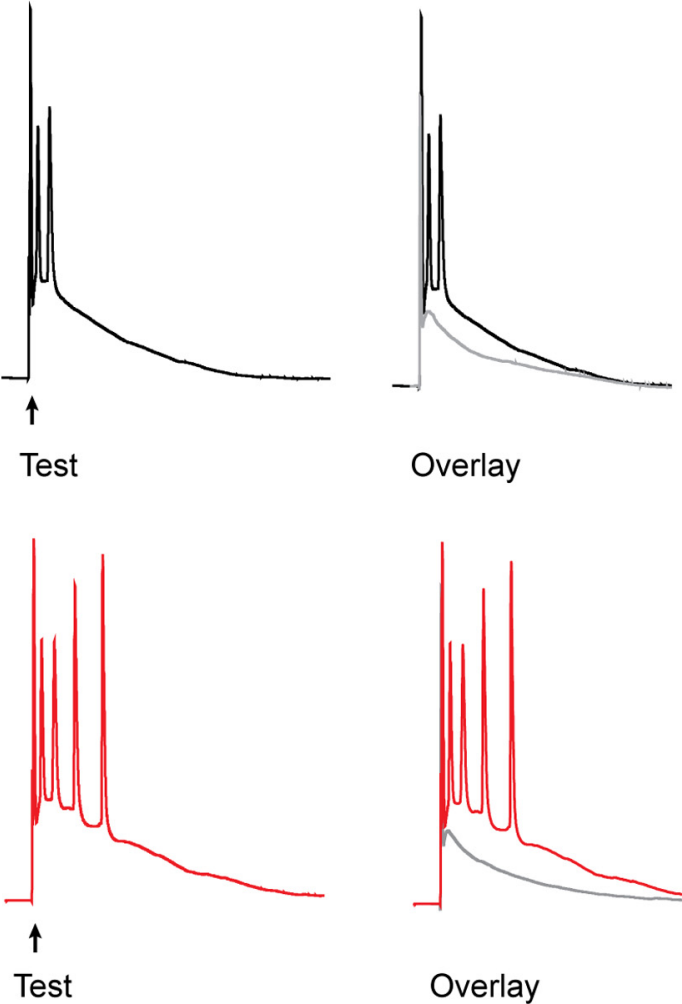

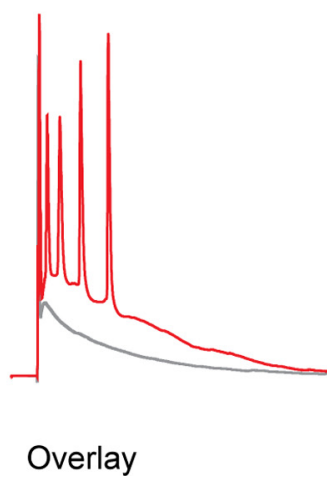

Figure 1. Post-train enhancement in both WT and Car14 KO. A single control stimulus to the Schaffer collaterals was followed after $2 \mathrm{~s}$ by a $10-$ pulse, $100 \mathrm{~Hz}$ train. At $2 \mathrm{~s}$ after the start of the train, a single test stimulus was applied. $\boldsymbol{A}$, WT responses to control stimulus, conditioning train, and test stimulus at $2 \mathrm{~s}$. Overlay of test response at $2 \mathrm{~s}$ (black) and control response (gray) is shown at far right. $\boldsymbol{B}, \mathrm{KO}$ responses to control stimulus, conditioning train, and test stimulus at $2 \mathrm{~s}$. Overlay of test response at $2 \mathrm{~s}$ (red) and control response (gray) is shown at far right. Calibration: single-stimulus responses, $20 \mathrm{mV}, 40 \mathrm{~ms}$; train responses, $20 \mathrm{mV}, 200 \mathrm{~ms}$.

For each cell, stimulus strength was adjusted to ensure that the ADP of the train response fully recovered to baseline membrane potential by $\sim 1 \mathrm{~s}$ before the test stimulus. Overall, return to baseline membrane potential occurred at $1034 \pm 41$ and $945 \pm$ $72 \mathrm{~ms}$ before the test stimulus in WT versus $\mathrm{KO}$, respectively $(~ p=$ 0.28 ). Thus, the control and test responses arose from the same baseline membrane potential and were elicited with equivalent temporal separation from the train response.

We observed no phenotypic difference in the pre-train control response, in terms of the number of spikes $(3.0 \pm 0.26 \mathrm{WT}$ vs $2.9 \pm 0.20 \mathrm{KO} ; p=0.76)$ or $\mathrm{HW}(51 \pm 3.3 \mathrm{WT}$ vs $56 \pm 3.7 \mathrm{~ms}$ $\mathrm{KO} ; p=0.31 ; n=30 \mathrm{WT}, 32 \mathrm{KO})$. The $\mathrm{HW}$ of the response to the $100 \mathrm{~Hz}$ stimulus train was also not different between WT and KO ( $p=0.75$; see below).

Relative to the control response, however, there was an enhancement of the test response that was evident in both WT and KO neurons. In the WT (Fig. $1 A$, top row), the HW of the test response was longer than the pre-train control, with a ratio of post-train/pre-train HW, or "enhancement ratio," of $1.71 \pm 0.14$ $(p<0.001)$. In addition, the control and test responses displayed $3.0 \pm 0.26$ versus $3.78 \pm 0.45$ spikes, respectively $(p<0.05)$, with an average of $0.81 \pm 0.38$ more spikes in the test response.

In the Car14 KO (Fig. 1B, top row), the enhancement ratio was $1.90 \pm 0.16(p<0.001)$, and the control and test responses displayed $2.9 \pm 0.20$ versus $5.14 \pm 0.48$ spikes, respectively $(p<$ 0.001 ), with an average of $2.3 \pm 0.41$ more spikes in the test response. Thus, the brief conditioning train led to increased excitability in both WT and KO preparations after a delay of $2 \mathrm{~s}$. This effect was not observed if the frequency of the 10-pulse conditioning train was reduced to 20 or $50 \mathrm{~Hz}$ (data not shown).
Detailed comparison of this enhancement in WT versus $\mathrm{KO}$ is provided further below.

To gain insight into the lifetime of the post-train enhancement, we compared the HW of a control response with a subsequent test responses 2, 10, or $48 \mathrm{~s}$ after onset of the conditioning train. At a delay of $10 \mathrm{~s}$, there was a variable persistence of the enhancement, which was not significantly different in eight WT versus nine $\mathrm{KO}$ cells, with mean enhancement ratios of $1.30 \pm$ 0.08 versus $1.25 \pm 0.06$, respectively $(p=0.60)$. In some cells, the enhancement noted at $2 \mathrm{~s}$ persisted at $10 \mathrm{~s}$, whereas in other cells, the effect had disappeared completely. Pooling all data, the enhancement observed at $2 \mathrm{~s}$ was reduced by $47 \pm 7.3 \%$ at $10 \mathrm{~s}$. By $48 \mathrm{~s}$, however, there was no residual effect in either WT or KO neurons, with a pooled HW ratio close to unity $(0.97 \pm 0.02 ; n=$ 17 cells). These results indicated that the enhancement was a short-lived phenomenon with a variable decay over a few seconds. In Figure 2, we show examples of the HWs at 2, 10, and $48 \mathrm{~s}$ for WT and KO.

\section{Enhancement was not presynaptic in origin}

To address whether the effect of the stimulus train on the test responses had a presynaptic basis, we recorded single EPSCs in whole-cell voltage clamp (holding potential of $-70 \mathrm{mV}$ ) and compared the amplitude of responses in an analogous stimulation paradigm (Fig. 3A). As judged by their fast rise time (10$90 \%$ ) of 2-3 ms, the evoked EPSCs were principally mediated by AMPARs, as expected at this negative holding potential (Hestrin et al., 1990). In contrast to the results in current clamp, a consistent depression of the test EPSCs was apparent in both preparations (Fig. 3B), with post-train/pre-train amplitude ratios of 
A
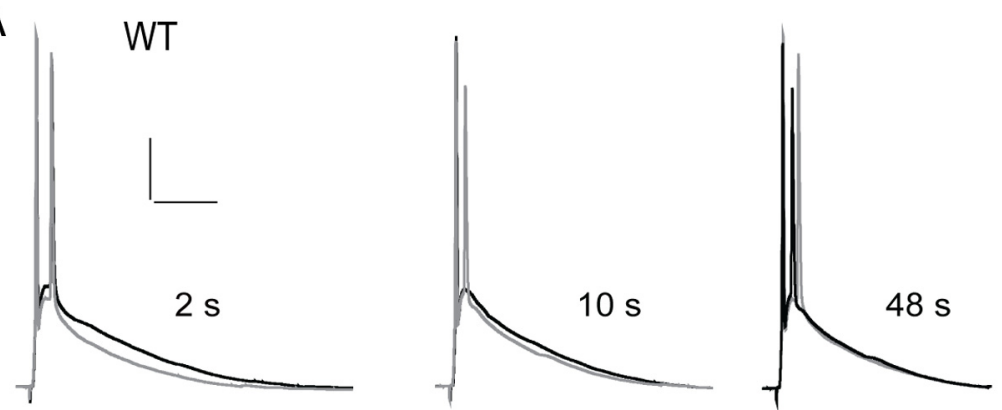

B
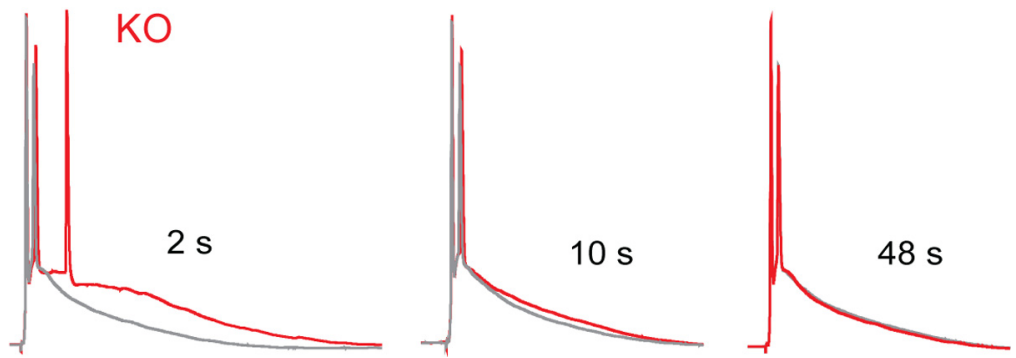

Figure 2. Post-train enhancement was short lived in both WT and Car14 K0. $\boldsymbol{A}$, WT test responses at 2, 10, and $48 \mathrm{~s}$ (black) overlaid with their respective control responses in gray. $\boldsymbol{B}, \mathrm{KO}$ test responses at 2,10 , and $48 \mathrm{~s}$ (red) overlaid with their respective control responses in gray. Calibration: $20 \mathrm{mV}, 40 \mathrm{~ms}$ for all traces.
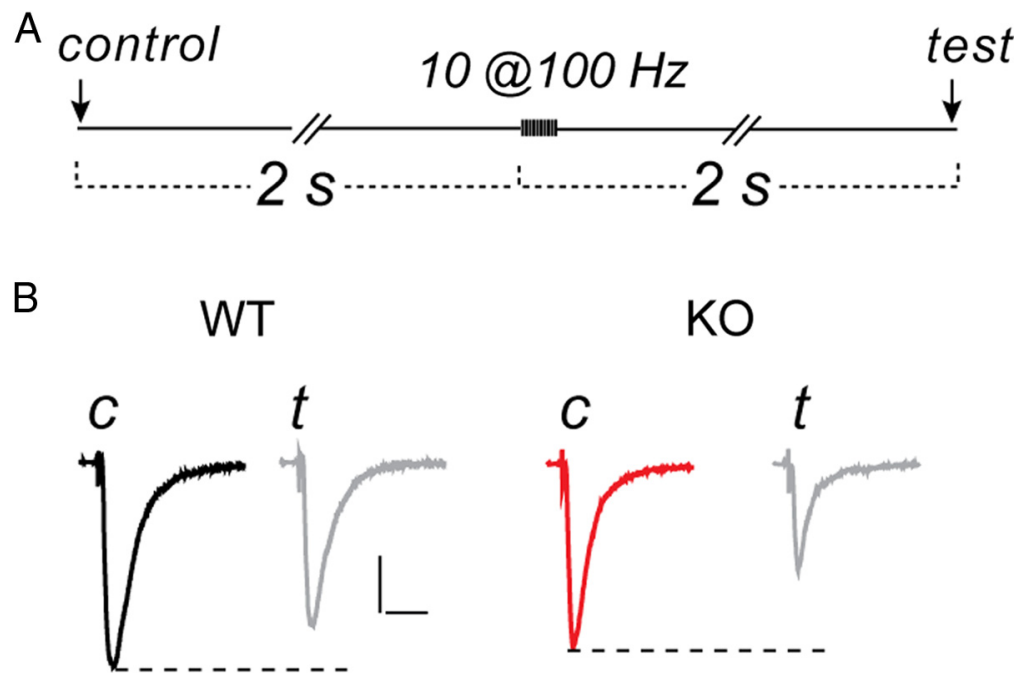

Figure 3. Short-term potentiation was not attributable to an increase in presynaptic transmitter release. $\boldsymbol{A}$, Schematic of stimulus paradigm. Control responses were evoked by a single stimulus, 2 s before a 10-pulse $(100 \mathrm{~Hz})$ train. Two seconds after onset of the train, a test response was evoked by another single stimulus. $\boldsymbol{B}$, Test EPSCs (t), shown in gray, were depressed after the brief stimulus train of 10 pulses at $100 \mathrm{~Hz}$. Control EPSCs (c) in WT and KO shown in black and red, respectively. Post- to pre-train amplitude ratios in these examples were 0.79 and 0.59 for WT and $K 0$, respectively. All traces are single, non-averaged responses with holding potential of $-70 \mathrm{mV}$. Calibration: WT, 140 pA, $20 \mathrm{~ms} ; \mathrm{KO}, 160 \mathrm{pA}, 20 \mathrm{~ms}$

$0.77 \pm 0.04$ versus $0.61 \pm 0.09$ for WT and $\mathrm{KO}$, respectively $(n=$ $5 \mathrm{WT}, n=6 \mathrm{KO} ; p=0.25)$. Similar depression of Schaffer collateral-evoked EPSCs was reported previously (Gipson and Yeckel, 2007). These results indicated that the enhanced test responses observed in current clamp could not be attributed to an increase in transmitter release. The effect was therefore unrelated to classical mechanisms of presynaptic plasticity, such as augmentation or post-tetanic potentiation (Zucker and Regehr, 2002). In addition, the enhancement could not have arisen from a less pronounced synaptic depression in the $\mathrm{KO}$ because there was no difference in this metric.
Post-train enhancement was greater in the Car14 KO

An immediate phenotypic difference was evident in the average number of additional spikes during the test response, which was nearly threefold greater for the Car14 KO, as noted above $(0.81 \pm 0.38$ vs $2.3 \pm 0.41$ spikes in WT and KO, respectively; $p=0.01$; Fig. 4A). Compared with WT, there was also a greater absolute $\mathrm{HW}$ of the test response in the $\mathrm{KO}(80 \pm 5.6$ vs $100 \pm 6.6 \mathrm{~ms}$, respectively; $p<0.01)$. Despite the differences in spike number and absolute HW, the enhancement ratios noted above were not significantly different $(1.71 \pm 0.14$ vs $1.90 \pm$ 0.16 , respectively; $p=0.38$ ).

To properly compare the enhancement ratio of WT versus $\mathrm{KO}$, the current-clamp response to the conditioning train should be uniform across all experiments. This was not the case, however, because the regenerative response to the $100 \mathrm{~Hz}$ stimulus train could not be controlled with precision. The ADP resulting from the train had a similar average $\mathrm{HW}$ in WT and $\mathrm{KO}(p=0.75)$, but its variability was considerable. Respective means were $560 \pm 30 \mathrm{~ms}$ (ranging from 279 to $790 \mathrm{~ms}$ ) versus $546 \pm 34 \mathrm{~ms}$ (ranging from 197 to $936 \mathrm{~ms}$ ). We noted that there was an overall positive correlation between the HWs of the train and test response $(r=$ $0.73 ; n=62$ ). Thus, a more prolonged train response appeared to cause greater enhancement. To further explore this notion, we accounted for the variability of the train response by normalizing the enhancement ratio to the train response $\mathrm{HW}$ for each cell. This metric was significantly greater in the $\mathrm{KO}$ (Fig. $4 B$, left). Thus, for a given train $\mathrm{HW}$, the enhancement ratio tended to be greater in the Car14 KO. When the number of additional spikes in the test response was similarly normalized to the train response $\mathrm{HW}$, the resulting metric remained significant, with an even lower $p$ value (Fig. $4 A$, right vs left).

Because the enhancement was the result of the conditioning train, a more direct measure of its effect is provided by the simpler ratio of test response HW to the train response $\mathrm{HW}$, without reference to the pretrain control. This normalized HW (NHW) was also significantly greater in the Car14 $\mathrm{KO}$ (Fig. 4B, right). Thus, in subsequent comparisons of $\mathrm{WT}$ versus $\mathrm{KO}$, in which $\mathrm{Mg}^{2+}$ was omitted from the ACSF, we focused exclusively on the test response $\mathrm{HW}$ or its NHW to assess the effect of the conditioning train.

\section{Post-train responses in $\mathbf{0} \mathrm{Mg}^{2+} /$ picrotoxin ACSF}

If the greater NHW of the Car14 KO were attributable to the influence of a train-evoked alkaline transient, one would expect an even more exaggerated effect on NHW in $0 \mathrm{Mg}^{2+}$ ACSF, because the additional $\mathrm{Ca}^{2+}$ entry via NMDARs should increase a PMCA-mediated alkalosis (Chen and Chesler, 1992b; Makani 
A
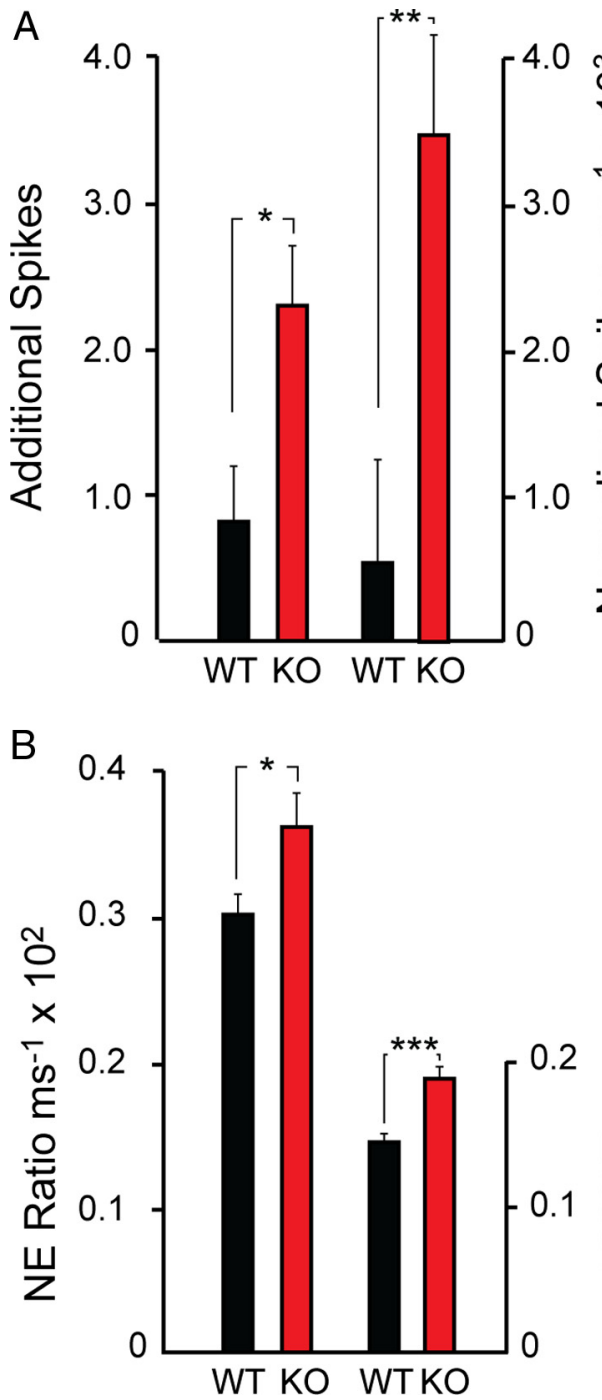

Figure 4. Increased effect of the conditioning train in the Car14 KO.A, The KO displayed more additional spikes in the test response (left). Normalizing the number of additional spikes to the HW of the train response (right) increased the level of significance. $\boldsymbol{B}$, The enhancement ratio (post-train HW/pre-train HW) was normalized to the HW of the train response. The resulting normalized enhancement ratio (NE Ratio, left), revealed greater duration of the test response per given duration of train response in the KO. The NHW of the test response (right) was also greater in the $\mathrm{KO}$ with a higher level of significance.

and Chesler, 2010). Additional experiments were therefore conducted in the absence of external $\mathrm{Mg}^{2+}$. To eliminate effects of $\mathrm{GABA}_{\mathrm{A}}$ receptor activation, which can elicit a different form of alkalosis attributable to $\mathrm{HCO}_{3}^{-}$efflux (Kaila and Voipio, 1987; Kaila et al., 1992), picrotoxin $(100 \mu \mathrm{M})$ was added to the $0 \mathrm{Mg}^{2+}$ ACSF.

For these experiments a 10 -pulse, $20 \mathrm{~Hz}$ train was implemented, followed by a single test pulse at $2 \mathrm{~s}$. Stimulus intensity was adjusted such that the train response recovered to baseline before the test stimulus. This resulted in mean train response HWs of $928 \pm 32 \mathrm{~ms}(n=24)$ and $993 \pm 48 \mathrm{~ms}(n=21)$ in WT versus $\mathrm{KO}$, respectively $(p=0.25)$. Examples of approximately equivalent train and subsequent test responses for WT and KO are shown in Figure $5 A$. As noted for experiments in standard ACSF, control of the regenerative train response was difficult, and these responses varied considerably (ranges of 713-1393 and 686-1420 ms for WT and KO, respectively). Consequently, test response HWs were again normalized to the HW of the respec-
A $0 \mathrm{Mg}^{2+}$ Picrotoxin

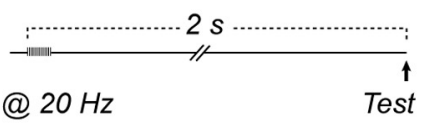

WT

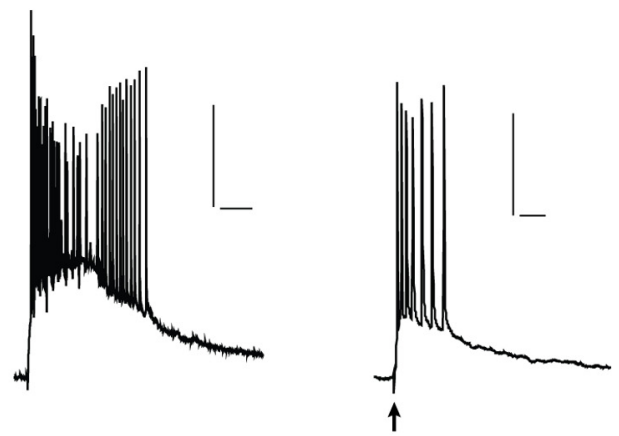

KO
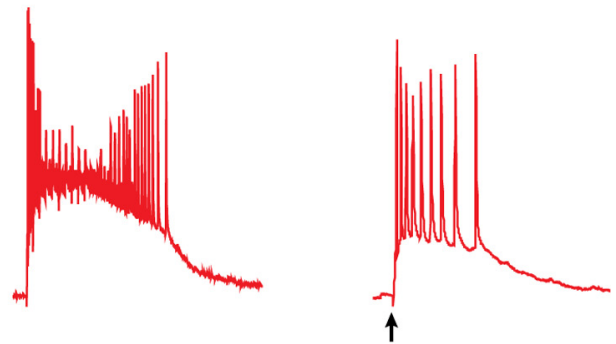

B

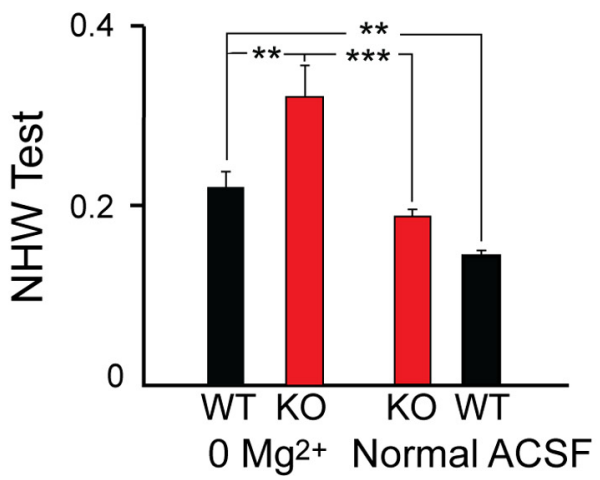

Figure 5. Post-train responses in $0 \mathrm{Mg}^{2+} /$ picrotoxin ACSF. $A$, Examples of responses from WT and Car14 K0. Test responses (arrows) followed a 10-pulse $(20 \mathrm{~Hz})$ stimulus train. ADPs of the test responses were more prolonged in Car14 KO compared with WT neurons. Calibration test responses, $40 \mathrm{mV}, 50 \mathrm{~ms}$; train responses, $40 \mathrm{mV}, 250$. B, Summary of NHW in WT and Car14 $\mathrm{KO}$ cells, in normal and $0 \mathrm{Mg}^{2+} /$ picrotoxin saline. Note that, in addition to greater NHW in Car14 K0, the NHW for both WT and KO was greater than the respective values in normal ACSF. Comparison of NHW for KO versus WT is shown in Figure 4 and omitted here for clarity. One-way ANOVA with Student-Newman-Keuls test.

tive, preceding train response. As in normal saline, the NHW was larger in the Car14 KO (Fig. 5B). Moreover, in both WT and KO, the NHW was increased approximately twofold compared with the respective values in normal ACSF (Fig. 5B). Given the greatly pronounced effect of the train on NHW in $0 \mathrm{Mg}^{2+}$ ACSF, we performed more extensive studies of the phenotypic difference using this saline.

\section{Evoked $\mathrm{pH}_{\mathrm{e}}$ shifts in $0 \mathrm{Mg}^{2+} /$ picrotoxin ACSF}

If the greater NHW in the Car14 KO were attributable to a larger peri-neuronal alkaline transient, this increased $\mathrm{pH}$ change might be evident in the amplitude of the macroscopic PAT, detected with fast-responding concentric $\mathrm{pH}$ electrodes (Fedirko et al., 2006). The PAT was recorded with $0 \mathrm{Mg}^{2+}$ saline/picrotoxin 
A

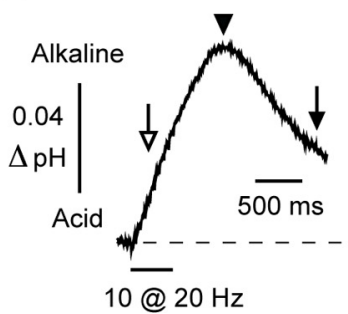

B

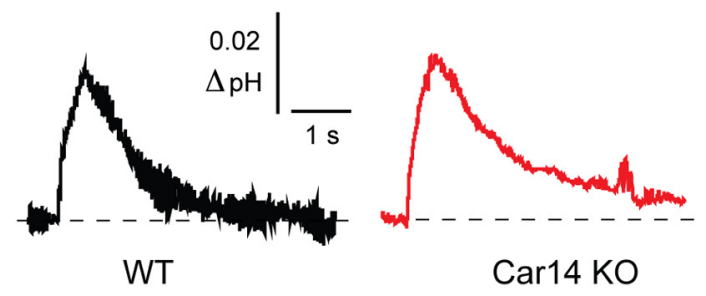

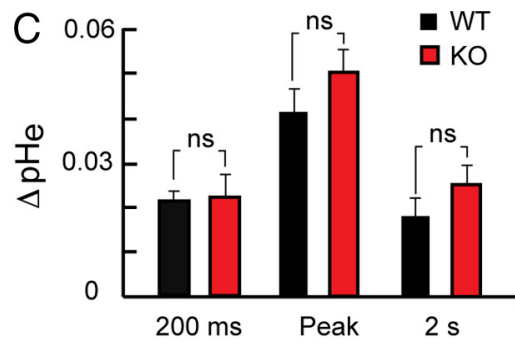

Figure 6. PATs in WT versus Car14 K0 slices were not different. $\boldsymbol{A}, \mathrm{In} 0 \mathrm{Mg}^{2+} /$ picrotoxin saline, PATs were evoked by a 10 -pulse (20 Hz) train, and amplitudes were measured at $200 \mathrm{~ms}$, the peak, and at $2 \mathrm{~s}$ after stimulus onset. $\boldsymbol{B}$, Representative PAT traces in WT versus Car14 K0 slices. C, Summary of PAT amplitudes in WT and Car14 K0 slices.

A

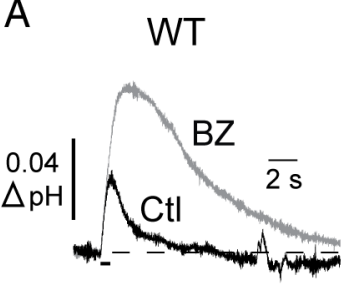

$\mathrm{B}$

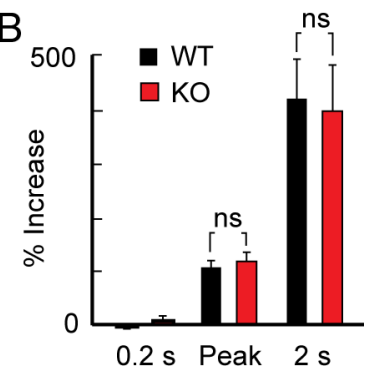

Figure 7. BZ caused a similar amplification of PATs in WT versus Car14 KO slices. A, Representative PATs evoked in $0 \mathrm{Mg}^{2+}$ / picrotoxin saline, before and after BZ. B, Summary of BZ effect on PAT amplitude at $200 \mathrm{~ms}$, peak, and $2 \mathrm{~s}$. Ctl, Control.

A
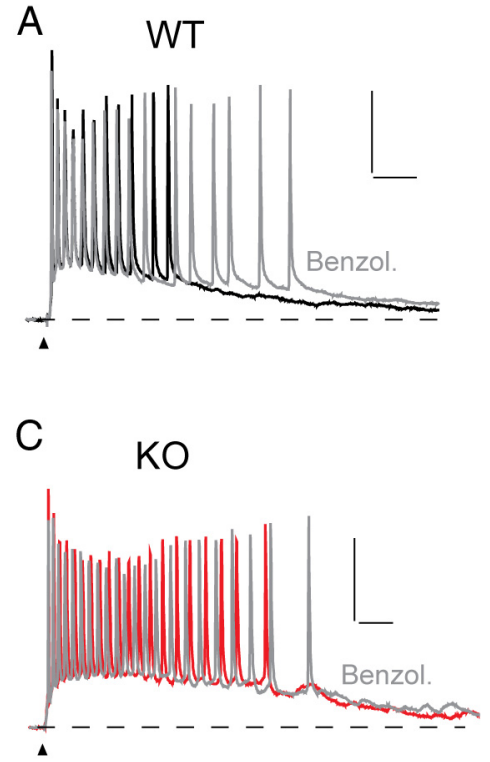
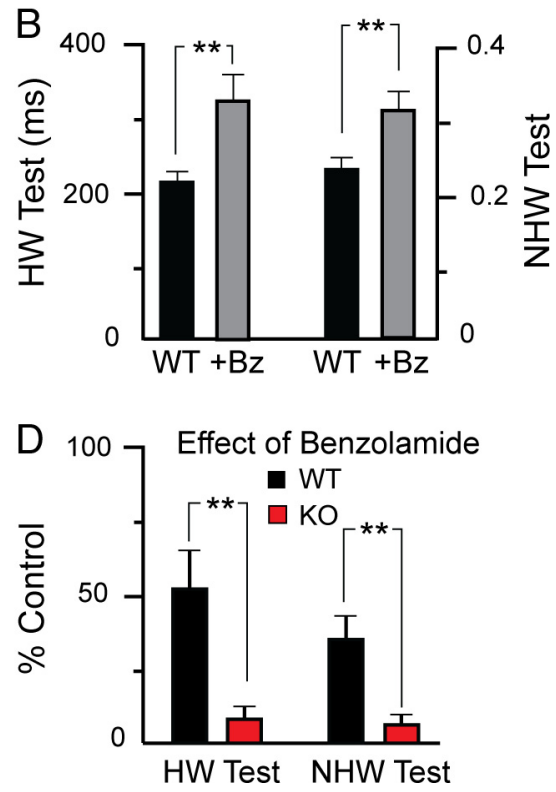

Figure 8. Effect of BZ on duration of test responses. $\boldsymbol{A}$, Representative traces of WT test response before (black) and after (gray) BZ. Train response not shown. Recordings conducted in $0 \mathrm{Mg}^{2+}$ / picrotoxin saline. $B$, Summary of BZ effect on HW and NHW of test response in WT cells. $C$, Representative traces of Car14 KO test response before (red) and after (gray) BZ. Note lack of BZ effect. Recordings conducted in $0 \mathrm{Mg}^{2+} /$ picrotoxin saline. Preceding train response not shown. D, Summary of BZ effect on HW and NHW of test response from WT versus Car14 K0 neurons. Calibration: $A, C, 40 \mathrm{mV}, 50 \mathrm{~ms}$.

ACSF in stratum radiatum, in response to a 10 -pulse, $20 \mathrm{~Hz}$ orthodromic train. Amplitude was measured at $200 \mathrm{~ms}$, the peak, and $2 \mathrm{~s}$ after the onset of stimulation (Fig. 6A). Examples of alkaline transients from WT and $\mathrm{KO}$ are presented in Figure $6 B$. As shown in Figure $6 C$, there was no significant difference between WT and KO at any of the three time points ( $p>0.2$ for all; $n=12$ slices WT, 14 slices $\mathrm{KO}$ ). Thus, within the extracellular volume sampled by a concentric $\mathrm{pH}$ electrode, absence of Car14 had no significant effect on the alkaline transient, as reported previously when antidromic PATs were measured in the CA1 cell body layer (Shah et al., 2005).

\section{The effect of $\mathrm{BZ}$ on orthodromic} responses in $\mathbf{0 ~} \mathrm{Mg}^{2+} /$ picrotoxin ACSF $\mathrm{BZ}$ is a poorly permeable Car inhibitor that slows the rate of extracellular buffering and thereby amplifies stimulus-evoked alkaline shifts (Chen and Chesler, 1992a). We compared its effect on the alkalinizations in WT versus Car14 KO (same slices as above). BZ $(10 \mu \mathrm{M})$ enlarged the $\mathrm{pH}$ shifts similarly in WT and KO (Fig. 7A). This indicated that the amplification was principally attributable to the inhibition of extracellular Car isoform 4. BZ had little or no effect during the early rise of the PAT, as reported previously (Tong et al., 2006). As shown in Figure $7 B$, amplification was evident at the peak and was especially pronounced at $2 \mathrm{~s}$ after onset of the stimulus train, corresponding to the relaxation phase of the alkalosis.

In a parallel set of whole-cell recordings, we tested the effects of $\mathrm{BZ}$ on the response to a 10-pulse, $20 \mathrm{~Hz}$ train and on the test responses that followed after $2 \mathrm{~s}$. In $24 \mathrm{WT}$ neurons, BZ modestly increased the HW of the train response (by $10 \pm$ $3.6 \% ; p<0.01)$ and caused a pronounced increase of both the test response HW $(52 \pm 13 \% ; p<0.01)$ and its NHW (35 \pm $7.9 \% ; p<0.001$ ) (Fig. $8 A, B$ ). In contrast, when BZ was added to the Car14 KO preparation, it had no effect on the $\mathrm{HW}$ of the train response, and there was no change in the HW or the NHW of the test response $(n=21$ cells; Fig. $8 C, D)$. It was notable that, in the WT, BZ increased the HW of the test response to a mean value identical to that of the $\mathrm{KO}$ in the absence of BZ $(323 \pm 37$ vs $323 \pm 47 \mathrm{~ms}$, respectively; $p=$ 0.99).

Similar experiments were conducted with the NMDAR antagonist MK-801 (1 mM) included in the patch pipette. After $15 \mathrm{~min}$ of dialysis, the HW of the test response was greatly curtailed, as would be expected after blockade of NMDARs. In five WT and five $\mathrm{KO}$ neurons, there was no difference between the test response HW or its NHW (Fig. 9A), and the subsequent addition of $\mathrm{BZ}$ had no effect on these parameters in either WT or KO neurons 
A
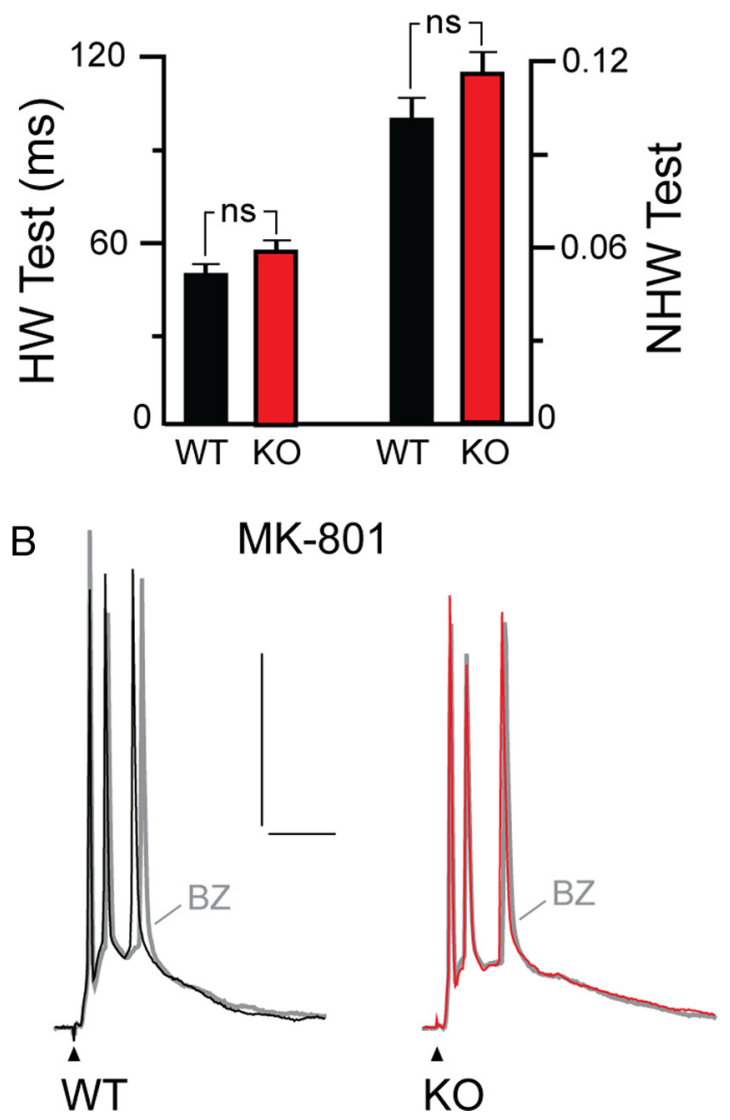

Figure 9. Differences between WT and Car14 KO were abolished by NMDAR antagonist. $A$, Summary HW and NHW of test responses with the noncompetitive NMDAR antagonist MK-801 $(1 \mathrm{~mm})$ in the patch pipette. $\boldsymbol{B}$, Representative traces of WT and Car14 K0 test responses in the presence of MK-801, before and after BZ. WT and KO ADPs shown in black and red, respectively. $B Z$ traces in gray. Note lack of BZ effect. Recordings conducted in $0 \mathrm{Mg}^{2+} /$ picrotoxin ACSF. Preceding train response not shown. Calibration: $40 \mathrm{mV}, 25 \mathrm{~ms}$.

(Fig. 9B). Thus, postsynaptic NMDARs were necessary to observe the effects of the Car14 KO.

\section{Discussion}

Our results demonstrated that the response of a CA1 pyramidal neuron to a single, orthodromic stimulus was augmented when elicited $2 \mathrm{~s}$ after a brief train in both WT and Car14 KO. This short-term potentiation did not result from an increase in presynaptic glutamate release because AMPAR-mediated EPSCs were depressed in an analogous paradigm. Although the mechanism of the post-train enhancement was not addressed in this study, the more pronounced effect in the Car14 KO, evident using a variety of metrics, suggested that a $\mathrm{pH}_{\mathrm{e}}$ shift played a role.

However, KO of Car14 did not alter PAT amplitude here or in a previous report (Shah et al., 2005). It should be stressed that, in such studies, $\mathrm{H}^{+}$activity is sampled from an extracellular compartment that encompasses several cellular elements (Nicholson and Phillips, 1981; Makani and Chesler, 2010) and thus comprises a volume orders of magnitude larger than the microdomains near the postsynaptic membrane. Because the amplitude of a local alkaline transient will fall off drastically with distance from its source (Makani and Chesler, 2010), it stands to reason that, in the microenvironment around the PMCA, the $\mathrm{pH}$ rise could be far greater than that discerned by a $\mathrm{pH}$ electrode. In fact, because hippocampal neurons express PMCA-2 splice variants at the postsynaptic density (DeMarco and Strehler, 2001; Burette et al., 2010), local alkaline shifts generated by the transporter are likely to occur in the immediate vicinity of postsynaptic NMDARs, fostering increased inward current and additional $\mathrm{Ca}^{2+}$ entry via these channels. Car14, by speeding the replenishment of protons in the microdomains around synapses, may therefore serve as a brake that limits this positive feedback onto NMDARs.

Interplay between Car14, the PMCA, and NMDARs may have additional implications for the physiology of excitatory synapses. Local decreases in extracellular $\mathrm{Ca}^{2+}$ arising from NMDAR activity may be mitigated as a result of the close proximity of the PMCA, which would replenish $\mathrm{Ca}^{2+}$ in the extracellular microdomain. Conversely, $\mathrm{Ca}^{2+}$ extrusion via the PMCA may be self-limiting because of the reduced availability of external protons in the vicinity of the transporter (leading to a more pronounced elevation of cytosolic $\mathrm{Ca}^{2+}$; Fedirko et al., 2007). Thus, the rate at which protons can be delivered to the PMCA may be an important parameter governing $\mathrm{Ca}^{2+}$ dynamics. The limited ability of the solvent to supply protons at sufficient rates (Barros and Martínez, 2007) is likely compensated by the catalyzed hydration of $\mathrm{CO}_{2}$ via Car14. In addition, non-catalytic delivery of protons via this enzyme could be relevant, as was described recently for Car2, in which the enzyme behaved as a proton harvesting "antenna" (Becker et al., 2011).

Especially stark differences between WT and $\mathrm{KO}$ were evident in $0 \mathrm{Mg}^{2+}$ saline, in which NMDAR-mediated $\mathrm{Ca}^{2+}$ entry, and related evoked alkalosis, would be more pronounced. Because these experiments were conducted in the presence of picrotoxin, the phenotypic difference could not be attributed to $\mathrm{pH}$ shifts arising from $\mathrm{HCO}_{3}^{-}$efflux across $\mathrm{GABA}_{\mathrm{A}}$ receptors (Kaila and Voipio, 1987; Kaila et al., 1992). Use of BZ in this media provided additional insight. Although amplification of the PAT was similar in $\mathrm{WT}$ and $\mathrm{KO}$, this Car inhibitor produced a striking difference in the whole-cell responses. In WT, both the HW and NHW of the test response were greatly increased, but the drug had no effect on these parameters in the KO. In fact, the prolonged HW of the WT in the presence of $\mathrm{BZ}$ was indistinguishable from that of the $\mathrm{KO}$ without the inhibitor. Thus, in the absence of Car14, the effects of BZ on the ADP appeared occluded.

These data argue that Car14 is important in governing perisynaptic $\mathrm{pH}$ and $\mathrm{ADP}$ duration but plays little role in catalysis of buffering in the broader, macroscopic, extracellular domain. In contrast, Car4 appeared to have little impact on ADP duration, because BZ had no effect on response HW in the Car14 KO. Thus, from the standpoint of buffering and the regulation of alkaline transients, Car4 clearly controls the macroscopic extracellular domain but may have little role in the microdomain near postsynaptic NMDARs.

The fundamental design of this study invoked a role for a perisynaptic alkalosis that would relieve the proton block on NMDARs. The implication of an extracellular Car and the proximity of the PMCA to postsynaptic NMDARs (DeMarco and Strehler, 2001; Burette et al., 2010) lend credence to these concepts. It should be noted, however, that neither the amplitude nor the time course of the perisynaptic alkalosis has been directly measured. Additional caveats should also be raised when considering the basis for post-train enhancement per se. There are several inter-related ionic shifts that accompany a brief $100 \mathrm{~Hz}$ stimulus train that might augment postsynaptic excitability. In addition to an extracellular alkaline transient, these may include a rise in extracellular $\mathrm{K}^{+}$and a fall in extracellular $\mathrm{Ca}^{2+}$ at distal dendritic sites (Nicholson et al., 1978), as well as alkaline shifts 
that can arise from $\mathrm{HCO}_{3}^{-}$efflux across $\mathrm{GABA}_{\mathrm{A}}$ receptors (Kaila and Voipio, 1987; Kaila et al., 1992). Although the basis for the post-train enhancement is not yet clear, a role for a PMCAmediated extracellular alkalosis in this effect represents the most parsimonious explanation for the robust phenotypic differences observed.

Finally, roles for Car14 other than buffering per se should be considered. The facilitation of $\mathrm{HCO}_{3}^{-}$transport is a function commonly associated with extracellular Car (McMurtrie et al., 2004), and hippocampal neurons express an inward, electrogenic $\mathrm{Na}^{+}-\mathrm{HCO}_{3}^{-}$cotransporter (Bevensee et al., 2000; Schmitt et al., 2000) that is activated during depolarization (Svichar et al., 2011). During a prolonged ADP, this transporter might bias local $\mathrm{pH}_{\mathrm{e}}$ in a relative acid direction. Other mechanisms, including an electroneutral $\mathrm{Na}^{+}-\mathrm{HCO}_{3}^{-}$cotransporter (Cooper et al., 2005) and $\mathrm{Na}^{+}-\mathrm{H}^{+}$exchange (Dietrich and Morad, 2010), could also contribute to acidification of the perisynaptic fluid. If Car14 normally facilitated these processes, then its absence might engender a relative extracellular alkalosis that would boost an ADP. However, a facilitative role in transport of $\mathrm{HCO}_{3}^{-}$or protons would not exclude a role for Car14 in buffering the PMCA-mediated alkalosis.

In summary, the present results have demonstrated a shortlasting increase in the orthodromic response of pyramidal neurons when activated $2 \mathrm{~s}$ after a brief stimulus train. One factor in this potentiation may be the generation of an alkalosis by the train, which boosts the post-train response. More extensive studies will be required to elucidate the mechanism of this enhancement. Our data, however, indicate that the enhancement is normally mitigated by Car 14, in keeping with a role for an alkaline $\mathrm{pH}$ transient. The potentiation had a marked effect on excitability, especially in view of the concomitant presynaptic depression. The enhancement was observed after a 100 $\mathrm{Hz}$, but not a 50 or $20 \mathrm{~Hz}$, conditioning train. This may be an indication of a Car14-sensitive, postsynaptic tuning, in which particular frequencies or patterns of afferent input maximally engender an alkalosis that boosts the ADP and promotes repetitive firing. Modulation of Car 14 activity could be a means of affecting this tuning.

A compelling question is whether this enzyme functions similarly in vivo. The brain slice preparation does not fully mimic the normal microenvironment in vivo and shifts in excitability arising from elevated oxygen (Garcia et al., 2010) or carbon dioxide levels (Voipio and Kaila, 1993) warrant consideration. However, altered flash electroretinograms in the Car14 KO mouse have been reported, suggesting that this enzyme does play a role in a rapid electrophysiological context in vivo (Ogilvie et al., 2007). In hippocampus, normal excitatory responses of CA1 neurons typically consist of high-frequency bursts on the order of 100-200 Hz (Fox and Ranck, 1975; Harris et al., 2001). Given that the activity of a single pyramidal cell can generate a measurable alkalosis on the surface of its dendrites (Makani and Chesler, 2010), it appears likely that in vivo activity gives rise to local increases in $\mathrm{pH}_{\mathrm{e}}$ that would be subject to regulation by Car14. Thus, the absence of Car14 might impact hippocampal-dependent learning and memory, but more targeted deletions of this enzyme would be required to better address this issue.

\section{References}

Barros LF, Martínez C (2007) An enquiry into metabolite domains. Biophys J 92:3878-3884. CrossRef Medline

Becker HM, Klier M, Schüler C, McKenna R, Deitmer JW (2011) Intramolecular proton shuttle supports not only catalytic but also noncata- lytic function of carbonic anhydrase II. Proc Natl Acad Sci U S A 108:3071-3076. CrossRef Medline

Bevensee MO, Schmitt BM, Choi I, Romero MF, Boron WF (2000) An electrogenic $\mathrm{Na}(+)-\mathrm{HCO}(-)(3)$ cotransporter $(\mathrm{NBC})$ with a novel COOH-terminus, cloned from rat brain. Am J Physiol Cell Physiol 278:C1200-C1211. Medline

Burette AC, Strehler EE, Weinberg RJ (2010) A plasma membrane $\mathrm{Ca}^{2+}$ ATPase isoform at the postsynaptic density. Neuroscience 169:987-993. CrossRef Medline

Chen JC, Chesler M (1992a) Modulation of extracellular pH by glutamate and GABA in rat hippocampal slices. J Neurophysiol 67:29-36. Medline

Chen JC, Chesler M (1992b) Extracellular alkaline shifts in rat hippocampal slice are mediated by NMDA and non-NMDA receptors. J Neurophysiol 68:342-344. Medline

Chesler M (2003) Regulation and modulation of $\mathrm{pH}$ in the brain. Physiol Rev 83:1183-1221. Medline

Cooper DS, Saxena NC, Yang HS, Lee HJ, Moring AG, Lee A, Choi I (2005) Molecular and functional characterization of the electroneutral $\mathrm{Na}$ / $\mathrm{HCO}_{3}$ cotransporter NBCn1 in rat hippocampal neurons. J Biol Chem 280:17823-17830. CrossRef Medline

DeMarco SJ, Strehler EE (2001) Plasma membrane $\mathrm{Ca}^{2+}$-atpase isoforms $2 \mathrm{~b}$ and $4 \mathrm{~b}$ interact promiscuously and selectively with members of the membrane-associated guanylate kinase family of PDZ (PSD95/Dlg/ ZO-1) domain-containing proteins. J Biol Chem 276:21594-21600. CrossRef Medline

Dietrich CJ, Morad M (2010) Synaptic acidification enhances GABAA signaling. J Neurosci 30:16044-16052. CrossRef Medline

Fedirko N, Svichar N, Chesler M (2006) Fabrication and use of high-speed, concentric $\mathrm{H}^{+}$- and $\mathrm{Ca}^{2+}$-selective microelectrodes suitable for in vitro extracellular recording. J Neurophysiol 96:919-924. CrossRef Medline

Fedirko N, Avshalumov M, Rice ME, Chesler M (2007) Regulation of postsynaptic $\mathrm{Ca}^{2+}$ influx in hippocampal CA1 pyramidal neurons via extracellular carbonic anhydrase. J Neurosci 27:1167-1175. CrossRef Medline

Fox SE, Ranck JB Jr (1975) Localization and anatomical identification of theta and complex spike cells in dorsal hippocampal formation of rats. Exp Neurol 49:299-313. CrossRef Medline

Garcia AJ 3rd, Putnam RW, Dean JB (2010) Hyperbaric hyperoxia and normobaric reoxygenation increase excitability and activate oxygen-induced potentiation in CA1 hippocampal neurons. J Appl Physiol 109:804-819. CrossRef Medline

Gipson KE, Yeckel MF (2007) Coincident glutamatergic and cholinergic inputs transiently depress glutamate release at rat schaffer collateral synapses. J Neurophysiol 97:4108-4119. CrossRef Medline

Gottfried JA, Chesler M (1994) Endogenous $\mathrm{H}^{+}$modulation of NMDA receptor-mediated EPSCs revealed by carbonic anhydrase inhibition in rat hippocampus. J Physiol 478:373-378. Medline

Harris KD, Hirase H, Leinekugel X, Henze DA, Buzsáki G (2001) Temporal interaction between single spikes and complex spike bursts in hippocampal pyramidal cells. Neuron 32:141-149. CrossRef Medline

Hestrin S, Nicoll RA, Perkel DJ, Sah P (1990) Analysis of excitatory synaptic action in pyramidal cells using whole-cell recording from rat hippocampal slices. J Physiol 422:203-225. Medline

Huang W, Smith SE, Chesler M (1995) Addition of carbonic anhydrase augments extracellular $\mathrm{pH}$ buffering in rat cerebral cortex. J Neurophysiol 74:1806-1809. Medline

Kaila K, Voipio J (1987) Postsynaptic fall in intracellular pH induced by GABA-activated bicarbonate conductance. Nature 330:163-165. CrossRef Medline

Kaila K, Paalasmaa P, Taira T, Voipio J (1992) pH transients due to monosynaptic activation of GABAA receptors in rat hippocampal slices. Neuroreport 3:105-108. CrossRef Medline

Makani S, Chesler M (2007) Endogenous alkaline transients boost postsynaptic NMDA receptor responses in hippocampal CA1 pyramidal neurons. J Neurosci 27:7438-7446. CrossRef Medline

Makani S, Chesler M (2010) Rapid rise of extracellular pH evoked by neural activity is generated by the plasma membrane calcium ATPase. J Neurophysiol 103:667-676. CrossRef Medline

McMurtrie HL, Cleary HJ, Alvarez BV, Loiselle FB, Sterling D, Morgan PE, Johnson DE, Casey JR (2004) The bicarbonate transport metabolon. J Enzyme Inhib Med Chem 19:231-236. CrossRef Medline

Nicholson C, Phillips JM (1981) Ion diffusion modified by tortuosity and 
volume fraction in the extracellular microenvironment of the rat cerebellum. J Physiol 321:225-257. Medline

Nicholson C, ten Bruggencate G, Stöckle H, Steinberg R (1978) Calcium and potassium changes in extracellular microenvironment of cat cerebellar cortex. J Neurophysiol 41:1026-1039. Medline

Ogilvie JM, Ohlemiller KK, Shah GN, Ulmasov B, Becker TA, Waheed A, Hennig AK, Lukasiewicz PD, Sly WS (2007) Carbonic anhydrase XIV deficiency produces a functional defect in the retinal light response. Proc Natl Acad Sci U S A 104:8514-8519. CrossRef Medline

Parkkila S, Parkkila AK, Rajaniemi H, Shah GN, Grubb JH, Waheed A, Sly WS (2001) Expression of membrane-associated carbonic anhydrase XIV on neurons and axons in mouse and human brain. Proc Natl Acad Sci U S A 98:1918-1923. CrossRef Medline

Schmitt BM, Berger UV, Douglas RM, Bevensee MO, Hediger MA, Haddad GG, Boron WF (2000) Na/HCO3 cotransporters in rat brain: expression in glia, neurons, and choroid plexus. J Neurosci 20:6839-6848. Medline

Schwiening CJ, Kennedy HJ, Thomas RC (1993) Calcium-hydrogen exchange by the plasma membrane Ca-ATPase of voltage-clamped snail neurons. Proc Biol Sci 253:285-289. CrossRef Medline

Shah GN, Ulmasov B, Waheed A, Becker T, Makani S, Svichar N, Chesler M, Sly WS (2005) Carbonic anhydrase IV and XIV knockout mice: roles of the respective carbonic anhydrases in buffering the extracellular space in brain. Proc Natl Acad Sci U S A 102:16771-16776. CrossRef Medline

Svichar N, Esquenazi S, Chen HY, Chesler M (2011) Preemptive regulation of intracellular $\mathrm{pH}$ in hippocampal neurons by a dual mechanism of depolarization-induced alkalinization. J Neurosci 31:6997-7004. CrossRef Medline

Tang CM, Dichter M, Morad M (1990) Modulation of the N-methyl-Daspartate channel by extracellular $\mathrm{H}^{+}$. Proc Natl Acad Sci U S A 87:64456449. CrossRef Medline

Tong CK, Chen K, Chesler M (2006) Kinetics of activity-evoked pH transients and extracellular $\mathrm{pH}$ buffering in rat hippocampal slices. J Neurophysiol 95:3686-3697. CrossRef Medline

Traynelis SF, Cull-Candy SG (1990) Proton inhibition of N-methyl-Daspartate receptors in cerebellar neurons. Nature 345:347-350. CrossRef Medline

Voipio J, Kaila K (1993) Interstitial PCO2 and pH in rat hippocampal slices measured by means of a novel fast $\mathrm{CO} 2 / \mathrm{H}(+)$-sensitive microelectrode based on a PVC-gelled membrane. Pflugers Arch 423:193-201. CrossRef Medline

Vyklick ý L Jr, Vlachov á V, Krůsek J (1990) The effect of external pH changes on responses to excitatory amino acids in mouse hippocampal neurones. J Physiol 430:497-517. Medline

Whittington DA, Grubb JH, Waheed A, Shah GN, Sly WS, Christianson DW (2004) Expression, assay, and structure of the extracellular domain of murine carbonic anhydrase XIV: implications for selective inhibition of membrane-associated isozymes. J Biol Chem 279:7223-7228. CrossRef Medline

Zucker RS, Regehr WG (2002) Short-term synaptic plasticity. Annu Rev Physiol 64:355-405. CrossRef Medline 